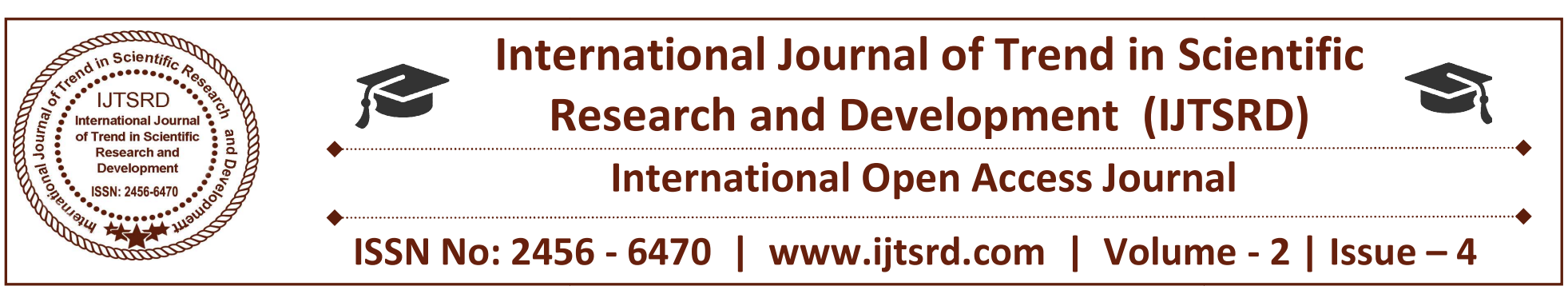

\title{
A Study on Preference of Learning Style in Relation to Academic Achievement in Commerce Among Higher Secondary School Students

\author{
Mrs. Ananthi ${ }^{1}$, Dr. Eagavalli ${ }^{2}$ \\ ${ }^{1}$ Student, ${ }^{2}$ Professor, \\ ${ }^{1,2}$ RVS College of Education, Coimbatore, Tamil Nadu, India
}

\begin{abstract}
The main purpose of this research was to investigating the relationship between learning styles of school students and their academic achievement based on their majors (major course of study in high school). The target population was school students of Coimbatore city including 300 students. By means of multi stage randomly sampling method, 300 individuals were selected as sample of research. By descriptive - survey research method and a questionnaire required data were collected. According to the results sensing intuitive learning styles shows significant correlations with academic achievement of students whose major was mathematics science. Academic achievement of students whose major was speculative science shows significant correlation with active-reflective learning styles. In students with empirical science, academic achievement shows significant correlation with both input dimension (visual-verbal) and understand dimension (sequentialglobal) of learning.
\end{abstract}

\section{INTRODUCTION}

Learning occupies a very important place in human life. It is a lifelong process. Learning is said to be equivalent to change, modification, development, improvement and adjustment. It is not confined to school learning, cycling, reading, writing or typing but it is comprehensive term which leaves a permanent effect or impression on the individuals. Man is a rational animal. He has got the power of reasoning. This power enables him to learn things quickly. Learning plays a very important role in determining behaviour of an individual. It is the basis of success in life. The miracles of present day civilization are the result of learning. Learning occupies very important role in the field of education.

We want to educate the students and it is only learning which is education. In order to develop presentation and communication techniques that facilitate effective learning, a teacher must have some notions how pupils learn. Course lectures and school experiences add to and reveal the very great differences in how individuals learn. Human behaviour, motivation, achievement, personality and self esteem, have impact on the activity of learning.

Active learning occurs when the pupil has some responsibility for the development of the activity. Supporters of this approach recognize that a sense of ownership and personal involvement is the key to successful learning. Active learning can be defined as purposeful interaction with ideas, concepts and can involve reading, writing, listening, talking or working with tools, equipment and material such as paint, wood, chemicals etc. In a simple sense, it is learning by doing. Active learning is contrasted with experiential learning. Experiential learning is also learning by doing but with the additional feature of reflection upon both action and the results of the action. Active learning strategies benefit both teachers and pupils. As a teacher, they enable to spend more time with groups or individuals which allows better uality assessment to take place. For the pupils activity method encourage autonomous learning and problem solving skills, important to both academic and vocationally based work. The advantages of active learning to pupils include greater personal satisfaction, more interaction with peers and opportunities to all members of the class to contribute and respond. It encourages mutual respect and appreciation of the viewpoint of others. Active learning is supportive of co-operative learning, not 
competitive learning. Active learning methods permote habits of learning which, it is hoped, are valuable in the workplace, in the home, and which generally enhance pupils capacity to cope with everyday life. School can be a place where pupils learn to do things well and in a certain ways. Skills are developed which are used throughout life. Pupils learn to consult a dictionary in order to find feeling or to counteract poor spellings. These skills become habits capable of reinforcement and development. Reinforcement leads to improved performance.

Styles by contrast, are static and are relatively in-built features of an individual. The style is the most pervasive phenomena of the contemporary society. Different writers have used this term in a variety of contexts. However in the field of psychology, it has been used in the context of personality, cognition, communication, motivation, perception, teaching, learning, leadership, decision making and problem solving etc. Thus the concept of style has been most often used to indicate an individuals quality or behaviour sustained over the time. It represents a distinct notion of coherent similarity in a variety of context.

\section{Review of Literature}

AlQahtani, N., AlMoammar, K., Taher, S., AlBarakati, S., \& AlKofide, E. (2018) examined the learning style preferences of undergraduate dental students and determine the influence of gender on their selection. This descriptive, cross-sectional study was conducted at the College of Dentistry, King Saud University, in Riyadh, Saudi Arabia, from September 2016 to January 2017.The Arabic version of visual, audio, read/write, and kinaesthetic questionnaire was administered to students from the first to the fifth academic year. Data was analysed using SPSS 21. P0.05 was considered significant. Of the 491 students, 368(75.1questionnaire. Of them, 269(73.1differences were found when learning styles were compared (p0.05). No significant differences could be found when the models were assessed as in the unimodal, bimodal, trimodal or quadmodal methods (p0.05). A significant difference was found between genders when learning styles were compared $(p=0.05)$. Males preferred the unimodal style, while females preferred the bimodal and quadmodal styles almost equally (p0.05).Most dental undergraduate students preferred multi-modal learning. Mitchell, T., Cohen, W., Hruschka, E., Talukdar, P., Yang, B., Betteridge, J., ... \& Krishnamurthy, J. (2018) learnt many different types of knowledge from diverse experiences over many years, and become better learners over time, most current machine learning systems are much more narrow, learning just a single function or data model based on statistical analysis of a single data set. We suggest that people learn better than computers precisely because of this difference, and we suggest a key direction for machine learning research is to develop software architectures that enable intelligent agents to also learn many types of knowledge, continuously over many years, and to become better learners over time. In this paper we define more precisely this never-ending learning paradigm for machine learning, and we present one case study: the Never-Ending Language Learner (NELL), which achieves a number of the desired properties of a never-ending learner. NELL has been learning to read the Web $24 \mathrm{hrs}$ /day since January 2010, and so far has acquired a knowledge base with $120 \mathrm{mn}$ diverse, confidence-weighted beliefs (e.g., served With (tea, biscuits)), while learning thousands of interrelated functions that continually improve its reading competence over time. NELL has also learned to reason over its knowledge base to infer new beliefs it has not yet read from those it has, and NELL is inventing new relational predicates to extend the ontology it uses to represent beliefs. We describe the design of NELL, experimental results illustrating its ehavior, and discuss both its successes and shortcomings as a case study in never-ending learning. Al-Qirim, N., Tarhini, A., Rouibah, K., Mohamd, S., Yammahi, A. R., \& Yammahi, M.A. (2018) examined the learning preferences of students in UAE University (UAEU). The uniqueness of this research emanates from the fact that no prior research examined this area from the UAEs perspective. Thus, this research embarks on the fact that student learning strategies vary from one country to another due to many factors. This research utilizes six learning strategies extended from the literature and attempts to examine their importance on UAEU students using survey research. The selected learning strategies were students motivation, time-poorness, mastery effort, assessment focus, competitiveness, and listening. This research provided interesting insights and contrasts pertaining to the learning strategies of UAEU students. Implications are discussed highlighting different theoretical as well as professional contributions and contentions and portrayed a path where pending issues could be addressed by future research. Kirschner, P. A. (2017) studied multitude of ways, and as such we also prefer many different 
things whether it is music, food or learning. Because of this, many students, parents, teachers, administrators and even researchers feel that it is intuitively correct to say that since different people prefer to learn visually, auditively, kinesthetically or whatever other way one can think of, we should also tailor teaching, learning situations and learning materials to those preferences. Is this a problem? The answer is a resounding: Yes! Broadly speaking, there are a number of major problems with the notion of learning styles. First, there is quite a difference between the way that someone prefers to learn and that which actually leads to effective and efficient learning. Second, a preference for how one studies is not a learning style. Most so-called learning styles are based on types; they classify people into distinct groups. The assumption that people cluster into distinct groups, however, receives very little support from objective studies. Finally, nearly all studies that report evidence for learning styles fail to satisfy just about all of the key criteria for scientific validity. This article delivers an evidence-informed plea to teachers, administrators and researchers to stop propagating the learning styles myth. Knoll, A. R., Otani, H., Skeel, R. L., \& Van Horn, K. R. (2017) proposed concept of learning style is immensely popular despite the lack of evidence showing that learning style influences performance. This study tested the hypothesis that the popularity of learning style is maintained because it is associated with subjective aspects of learning, such as judgements of learning (JOLs). Preference for verbal and visual information was assessed using the revised Verbalizer Visualizer Questionnaire (VVQ). Then, participants studied a list of word pairs and a list of picture pairs, making JOLs (immediate, delayed, and global) while studying each list. Learning was tested by cued recall. The results showed that higher VVQ verbalizer scores were associated with higher immediate JOLs for words, and higher VVQ visualizer scores were associated with higher immediate JOLs for pictures. There was no association between VVQ scores and recall or JOL accuracy. As predicted, learning style was associated with subjective aspects of learning but not objective aspects of learning. DeCoux, V. M. (2016) reviewed the application of the Kolb Learning Style Inventory (LSI) in the examination of learning styles among nursing students, as reported in the current literature. In general, a lack of significant relationships between learning style and other variables was revealed in the research on nursing students. In addition, studies undertaken specifically to investigate the measurement properties of the LSI reported major criticisms which seem to have been ignored. In spite of numerous charges of serious instrument weakness, the Kolb LSI has become the most frequently used method of measuring learning styles among nursing students. Continued use of the Kolb LSI in nursing research or as an experiential technique is not recommended. There has been a veritable deluge of research on learning styles among health professionals in recent years. Upon examination of the learning style literature, one finds a sometimes puzzling array of research. Not only are the terms learning styles and cognitive styles used almost indiscriminately, but also the sheer numbers of instruments used to measure these constructs are baffling. Nursing students are among the most frequently studied groups of health professionals with regard to the learning style construct. Demirkan, H. (2016) explored the learning-style and knowledge-building preferences of interior architecture students using Felder Solomans Index of Learning Styles. Considering the learning and knowledge-building skills of students in design education, this study concludes that the instructor should not only be a conveyor of knowledge but also a facilitator. The findings indicate that design students preferred learning styles are as follows, in descending order:Sensing/Intuitive, Visual/Verbal, Active/ Reflective and Sequential/Global. In the two-way analysis, where the students design studio grade was the dependent variable, significant effects were obtained for each scale. Furthermore, double interactions were highly significant between the Active/Reflective and Sensing/Intuitive scales and between the Active/Reflective and Sequential/Global scales. Rogowsky, B. A., Calhoun, B. M., \& Tallal, P. (2015) hypothesized that providing instruction based on individuals preferred learning styles improves learning (i.e., reading for visual learners and listening for auditory learners, also referred to as the meshing hypothesis), after a critical review of the literature Pashler, McDaniel, Rohrer, and Bjork (2008) concluded that this hypothesis lacks empirical evidence and subsequently described the experimental design needed to evaluate the meshing hypothesis. Following the design of Pashler et al., we empirically investigated the effect of learning style preference with college-educated adults, specifically as applied to (a) verbal comprehension aptitude (listening or reading) and (b) learning based on mode of instruction (digital audiobook or e-text). First, participants auditory and visual learning style preferences were established based on a standardized adult learning 
style inventory. Participants were then given a verbal comprehension aptitude test in both oral and written forms. Results failed to show a statistically significant relationship between learning style preference (auditory, visual word) and learning aptitude (listening comprehension, reading comprehension). Wilkinson, T., Boohan, M., \& Stevenson, M. (2014) learning styles has been conducted for some time, initially within the field of psychology. Recent research has widened to include more diverse disciplines, with greater emphasis on application. Although there are numerous instruments available to measure several different dimensions of learning style, it is generally accepted that styles differ, although the qualities of more than one style may be inherent in any one learner. But do these learning styles have a direct effect on student performance in examinations, specifically in different forms of assessment? For this study, hypotheses were formulated suggesting that academic performance is influenced by learning style. Using the Honey and Mumford Learning Style Questionnaire, learning styles of a cohort of first year medical and dental students at Queens University Belfast were assessed. Manolis, C., Burns, D. J., Assudani, R., \& Chinta, R. (2013) understand experiential learning, many have reiterated the need to be able to identify students learning styles. Kolbs Learning Style Model is the most widely accepted learning style model and has received a substantial amount of empirical support. Kolbs Learning Style Inventory (LSI), although one of the most widely utilized instruments to measure individual learning styles, possesses serious weaknesses. This study transforms the LSI from a type (categorical measure) to a degree (continuous measure) style of learning style measure that is not only more parsimonious but is also easier to use than the existing LSI. Two separate studies using samples of engineering and computer science graduate students (Study 1) and undergraduate and graduate students pursuing quantitative degrees (Study 2) culminating in a corroborative multi-sample validation were employed, producing a methodologically sound option to the existing LSI. Implications for future research and guidance for learning and teaching methods are discussed. Huang, E. Y., Lin, S. W., \& Huang, T. K. (2012)assumed to be a predictor of learning performance, yet few studies have identified the mediating and moderating effects between the two. This study extends previous research by proposing and testing a model that examines the mediating processes in the relationship between learning style and e-learning performance and the moderating effects of prior knowledge. The results show that the sensory/intuitive dimension of learning style predicts learning performance indirectly through the mediation of online participation. However, other types of learning styles do not affect online participation. Sensory students demonstrate a higher level and intuitive students a lower level of online participation. Prior knowledge plays an important role as a moderator between online participation and learning performance. This study was conducted in the context of software usage instruction using empirical data from 219 undergraduate students. Klanja-Milievi, A., Vesin, B., Ivanovi, M., \& Budimac, Z. (2011) Personalized learning occurs when e-learning systems make deliberate efforts to design educational experiences that fit the needs, goals, talents, and interests of their learners. Researchers had recently begun to investigate various techniques to help teachers improve e-learning systems. In this paper, we describe a recommendation module of a programming tutoring system - Protus, which can automatically adapt to the interests and knowledge levels of learners. This system recognizes different patterns of learning style and learners habits through testing the learning styles of learners and mining their server logs. Firstly, it processes the clusters based on different learning styles. Next, it analyzes the habits and the interests of the learners through mining the frequent sequences by the AprioriAll algorithm. Finally, this system completes personalized recommendation of the learning content according to the ratings of these frequent sequences, provided by the Protus system. Some experiments were carried out with two real groups of learners: the experimental and the control group. Learners of the control group learned in a normal way and did not receive any recommendation or guidance through the course, while the students of the experimental group were required to use the Protus system. The results show suitability of using this recommendation model, in order to suggest online learning activities to learners based on their learning style, knowledge and preferences.

\section{Objectives of the study}

1. To study the relationship between learning styles and academic achievement in commerce among higher secondary school students. 
2. To find out relationship between learning styles and academic achievement among commerce group students.

3. To find out the influence of independent variables like gender, boards of education, parents monthly income, medium of instruction and fathers and mothers educational qualification on learning styles among commerce group students.

4. To find out the influence of independent variables like gender, boards of education, parents monthly income, medium of instruction and fathers and mothers educational qualification on Academic achievement among commerce group students.

\section{Research Questions}

1. What are the learning styles in commerce among higher secondary school students?

2. What are the academic achievements in commerce among higher secondary school students?

3. Is there is any significant mean score difference in learning styles between boys and girls among commerce group school students? Is there is any significant mean score difference in academic achievement between boys and girls among commerce group school students?

4. Is there is any academic achievement changes due to educational qualification of their parent?

\section{Hypotheses}

1. There will be a significant mean score difference in learning styles between boys and girls among commerce group school students.

2. There will be a significant mean score difference in learning styles among students between the group based on their school location.

3. There will be a significant mean score difference in the learning styles among students between the group based on various boards of education.

4. There will be a significant mean score difference in the learning styles among students between the group based on medium of instruction.

\section{Variables}

An independent variable is a variable that is expected to influence the dependent variables. Its value may be changed or altered, which is independent of any other variables. Also the following demographic variables were used as independent variables.

$>$ Gender (Boys/Girls).

$>$ School Location (Rural/Urban).

$>$ Board of Education (State board/Matriculation).

$>$ Medium of study (Tamil/English)
Dependent variable are those events which are by

hypothesized as dependent on the changes in the dependent variable (Learning styles among the higher secondary school students).

\section{Design of the study}

In the presence study Normative survey method will be adopted. Survey research employee questioner and interview to our people who provide informations about them selfs their attitude and believes demographic (Age, Gender, Income and So on) the survey method can be classified into many, but according to the objectives and hypotheses in this presence study normative survey method will be adopted.

\section{Population and Sample}

Sulur is a town panchayat city in district of Coimbatore, Tamil nadu. Sulur is very rich with respected in Education. There are several Educational Institution in and around Sulur. Literacy rate of sulur taluk is $86.68 \%$. There are many higher secondary school in this area. Government higher secondary schools, Government aided higher secondary schools and Matriculation higher secondary schools.

\section{Sampling Techniques}

Sampling procedure is a definite plan determined before any data are actually collected for obtaining a sample from a given population under the simple random sampling technique. This sampling method is used for selecting samples. The study is based on primary data which is collected from 300 school students at higher high level and around Coimbatore district. The sample which was collected from various college located in and around Coimbatore is shown as below.

Table 1.1

List of schools used for data collection

\begin{tabular}{|c|c|c|}
\hline $\begin{array}{c}\text { S. } \\
\text { No }\end{array}$ & Name of the schools & $\begin{array}{c}\text { Number of } \\
\text { students }\end{array}$ \\
\hline 1. & GOVT BOYS HSS, SULUR & 52 \\
\hline 2. & GOVT GIRLS HSS, SULUR & 49 \\
\hline 3. & $\begin{array}{c}\text { KENNEDY MAT HSS } \\
\text { SCHOOL,SULUR }\end{array}$ & 48 \\
\hline 4. & $\begin{array}{c}\text { KALAIVANI MAT HSS } \\
\text { SCHOOL,SULUR }\end{array}$ & 51 \\
\hline 5. & $\begin{array}{c}\text { MICHAEL JOB MAT } \\
\text { SCHOOL,RAVATHUR }\end{array}$ & 47 \\
\hline 6. & GHSS KANNAMPALAYAM & 53 \\
\hline
\end{tabular}

TABLE 1.2

Distribution of samples based on variables

\begin{tabular}{|c|l|l|l|l|l|}
\hline $\begin{array}{c}\text { S. } \\
\text { No }\end{array}$ & Category & Subgroups & Number & $\%$ & Total \\
\hline
\end{tabular}


International Journal of Trend in Scientific Research and Development (IJTSRD) ISSN: 2456-6470

\begin{tabular}{|c|c|c|c|c|c|}
\hline \multirow{2}{*}{1.} & \multirow{2}{*}{ Gender } & Boys & 192 & 64 & \multirow{2}{*}{300} \\
\cline { 3 - 5 } 2. & Girls & 108 & 36 & \\
\hline \multirow{2}{*}{2.} & \multirow{2}{*}{ Locality } & Rural & 100 & 33 & \multirow{2}{*}{300} \\
\cline { 3 - 5 } & \multirow{2}{*}{ Board } & Urban & 200 & 67 & \\
\hline \multirow{2}{*}{4.} & $\begin{array}{c}\text { State } \\
\text { Board }\end{array}$ & 154 & 51 & \multirow{2}{*}{300} \\
\cline { 3 - 5 } & Medium & Matric & 146 & 49 & \\
\cline { 3 - 5 } & & Tamil & 154 & 51 & \multirow{2}{*}{300} \\
\hline
\end{tabular}

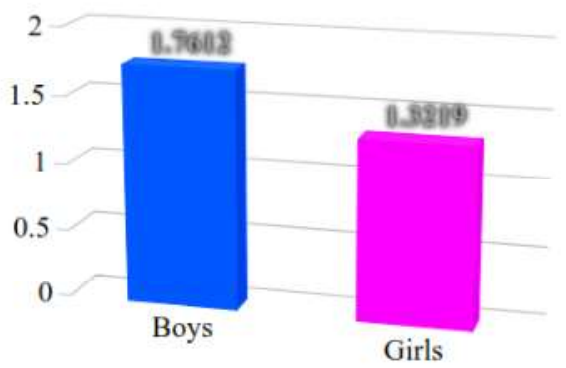

Figure 1:Relationship Between Students Gender and Learning Styles and Academic Achievement in Commerce Among Higher Secondary School Students

\section{Research Tool}

Tool becomes another major consideration in an education research. The instrument employed for the collection of data required for the study of any problem is called tool. Tool employ distinction way of describing and qualifying the data the important tools of educational research include interview schedule, questionnaire, observation, rating scale, proficiency test, psychological tests and sociogram.

\section{Testing Hypothesis 1:}

There will be a significant mean score difference in learning styles between boys and girls among commerce group school students.

\section{TABLE 1.3}

Mean Score difference and $t$ - value of factors related to learning styles and academic achievement in commerce among higher secondary school students based on gender

\begin{tabular}{|c|l|c|c|c|c|c|}
\hline $\begin{array}{c}\text { S. } \\
\text { No }\end{array}$ & Gender & N & Mean & Df & $\begin{array}{r}\text { t- } \\
\text { Value }\end{array}$ & $\begin{array}{l}\text { Re- } \\
\text { sult }\end{array}$ \\
\hline 1. & Boys & 112 & 1.2516 & 192 & 1.7612 & S \\
\cline { 1 - 3 } 2. & Girls & 118 & 1.3219 & & & \\
\hline \multicolumn{2}{|l|}{ Total } & 300 & 1.5416 & & & \\
\hline
\end{tabular}

The Table 1.3 shows the mean score difference in learning styles and academic achievement in commerce among higher secondary school students Based on gender (Boys/Girls). The calculate $t$ value is statistically a significance at 0.05 levels and hence the hypotheses 1 is accepted. It can be concluded that there is a significant difference in mean score difference in learning styles and academic achievement in commerce among higher secondary school students based on gender.

\section{Testing Hypothesis 2:}

There will be a significant mean score difference in learning styles and academic achievement in commerce among higher secondary school students based on School Location (Rural/Urban).

\section{TABLE 1.4}

Mean Score difference and $t$ - value of factors related to learning styles and academic achievement in commerce among higher secondary school students based on School Location (Rural/Urban).

\begin{tabular}{|c|l|c|c|c|c|c|}
\hline $\begin{array}{c}\text { S. } \\
\text { No }\end{array}$ & Locality & N & Mean & Df & $\begin{array}{c}\text { t- } \\
\text { Value }\end{array}$ & $\begin{array}{c}\text { Re- } \\
\text { sult }\end{array}$ \\
\hline 1. & Rural & 100 & 1.4722 & 292 & -2.311 & S \\
\hline 2. & Urban & 200 & 1.6212 & & & \\
\hline \multicolumn{2}{|l|}{ Total } & 300 & 1.5467 & & & \\
\hline
\end{tabular}

The Table 1.4 shows the mean score difference in learning styles and academic achievement in commerce among higher secondary school students based on School Location (Rural/ Urban).The calculate $t$ value is statistically a significance at 0.05 levels and hence the hypotheses 2 is accepted. It can be concluded that there is a significant difference in mean score difference in learning styles and academic achievement in commerce among higher secondary school students based on School Location

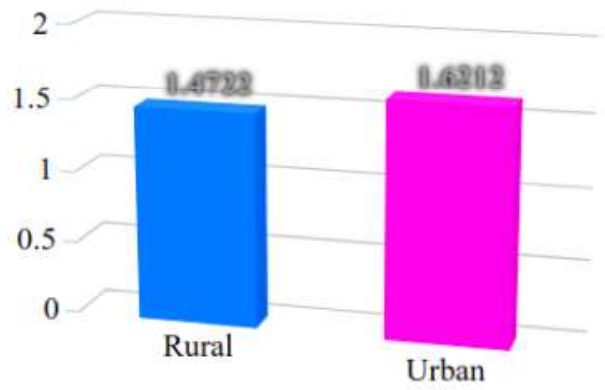

Figure 2:Relationship Between Students School

Location and Learning Styles and Academic Achievement in Commerce Among Higher Secondary School Students 
Testing Hypothesis 3:

There will be a significant mean score difference in learning styles and academic achievement in commerce among higher secondary school students based on Study Board.

\section{TABLE 1.5}

Mean Score difference and t- value of factors related to learning styles and academic achievement in commerce among higher secondary school students based on Study board

\begin{tabular}{|c|l|c|c|c|c|c|}
\hline $\begin{array}{c}\text { S. } \\
\text { No }\end{array}$ & Board & N & Mean & Df & $\begin{array}{c}\text { t- } \\
\text { Value }\end{array}$ & $\begin{array}{c}\text { Re- } \\
\text { sult }\end{array}$ \\
\hline 1. & $\begin{array}{l}\text { State } \\
\text { Board }\end{array}$ & 154 & 1.1325 & 299 & 0.991 & NS \\
\cline { 1 - 3 } 2. & Matric & 146 & 1.1021 & & & \\
\hline \multicolumn{2}{|l|}{ Total } & 300 & 1.1173 & & & \\
\hline
\end{tabular}

The Table 1.5 shows the mean score difference in learning styles and academic achievement in commerce among higher secondary school students based on Study board.The calculate $t$ value is statistically no significance at 0.05 levels and hence the hypotheses 3 is rejected. It can be concluded that there is no significant difference in mean score difference in learning styles and academic achievement in commerce among higher secondary school students based on Study board.

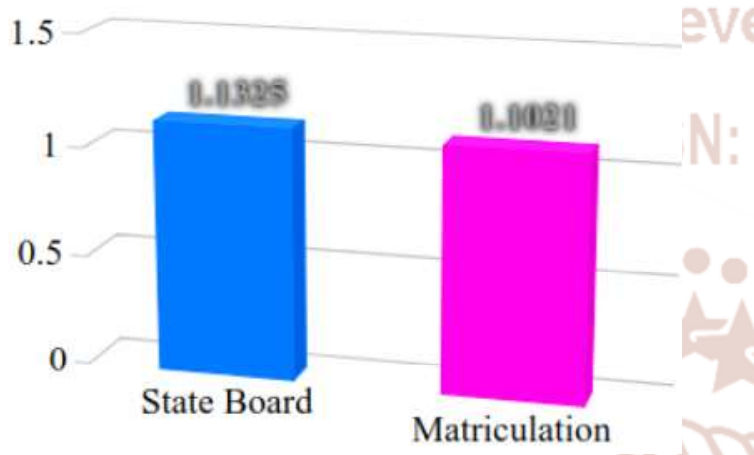

Figure 3:Relationship Between Student Study Board and Learning Styles and Academic Achievement in

Commerce Among Higher Secondary School Students

\section{Testing Hypothesis 4:}

There will be a significant mean score difference in learning styles and academic achievement in commerce among higher secondary school students based on Medium of study (Tamil/English)
TABLE 1.6

Mean Score difference and t- value of factors related to level of study on Ecological awareness of high school students in Coimbatore district based on parents annual income

\begin{tabular}{|c|c|c|c|c|c|c|}
\hline $\begin{array}{c}\text { S. } \\
\text { No }\end{array}$ & $\begin{array}{c}\text { Mediu } \\
\text { m }\end{array}$ & N & Mean & Df & $\begin{array}{c}\text { t- } \\
\text { Value }\end{array}$ & $\begin{array}{c}\text { Re- } \\
\text { sult }\end{array}$ \\
\cline { 1 - 3 } 1. & Tamil & 154 & 1.0481 & 299 & -2.215 & S \\
\cline { 1 - 3 } 2. & English & 146 & 1.3221 & & & \\
\hline \multicolumn{2}{|l|}{ Total } & 300 & 1.1851 & & & \\
\hline
\end{tabular}

The Table 1.6 shows the mean score difference in learning styles and academic achievement in commerce among higher secondary school students based on Medium of study (Tamil/English). The calculate $t$ value is statistically a significance at 0.05 levels and hence the hypotheses 4 is accepted. It can be concluded that there is a significant difference in mean score difference in learning styles and academic achievement in commerce among higher secondary school students based on Medium of Study.

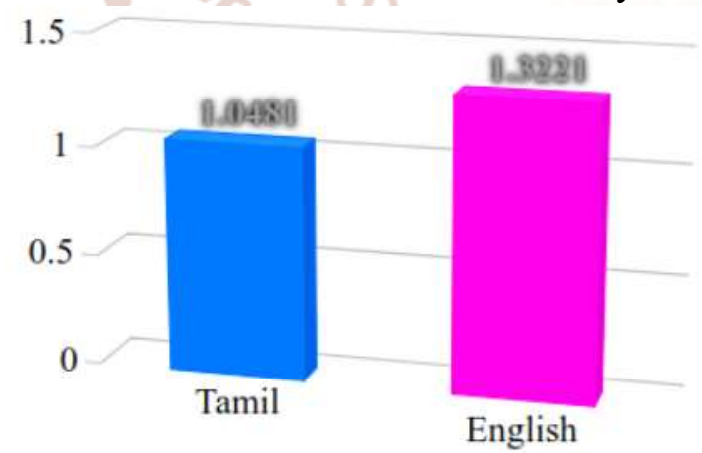

Figure 4:Relationship Between Medium of Study and Learning Styles and Academic Achievement in Commerce Among Higher Secondary School Students

\section{Findings of the study}

$>$ There is a significant relationship between gender and learning styles and academic achievement in commerce among higher secondary school students.

$>$ There is a significant relationship between locality related factors and learning styles and academic achievement in commerce among higher secondary school students.

$>$ There is no significant relationship between Board of education related factors and learning styles and academic achievement in commerce among higher secondary school students.

There is a significant relationship between medium of study and learning styles and academic achievement in commerce among higher secondary school students. 


\section{Summary}

$>$ A study on learning styles in relation to academic achievement among students was studied and the findings reveal that there is a significant difference between learning styles and academic achievement in commerce among higher secondary school students with respect to gender,locality and medium of study.

> A study on learning styles in relation to academic achievement among students was studied and the findings reveal that there is no significant difference between learning styles and academic achievement in commerce among higher secondary school students with respect to board of education.

\section{Limitations}

> The study has certain limitation, which are as follows:

$>$ Only 300 students are selected as sampling for the study.

> The project has been restricted to analyze and study in learning styles and its impact on academic achievement among students

$>$ The study is restricted to the school students of Sulur.

\section{Conclusion and Future Recommendations}

$>$ A Similar Study can be conducted for dissertation by taking more number of concepts and students.

$>$ The study can be conducted to other schools around Tamilnadu.

$>$ Present survey helps to investigate the study of teacher role for higher high students

$>$ A similar study can also be conducted using various variables.

The conclusion is that there is a significant relationship between gender, school location and medium of study on impact of learning styles among students .While taking decision on impact of learning styles among students their board of education has to be taken for decision making process.

\section{Bibliography}

1. AlQahtani, N., AlMoammar, K., Taher, S., 1Barakati, S., \& AlKofide, E. (2018). Learning preferences among dental students using the VARK questionnaire: A comparison between different academic levels and gender. JPMA. The Journal of the Pakistan Medical Association, 68(1), 59-64.
2. AAl-Qirim, N., Tarhini, A., Rouibah, K., Mohamd, S., Yammahi, A. R., \& Yammahi, M. A. (2018). Learning orientations of IT higher education students in UAE University. Education and Information Technologies, 23(1), 129-142..

3. Choudhary, R., Dullo, P., \& Tandon, R. V. (2011). Gender differences in learning style preferences of first year medical students. Pak J Physiol, 7(2), 42-45.

4. Jeelani, S., Sabesan, S., \& Subramanian, S. (2015). Community knowledge, awareness and preventive practices regarding dengue fever in PuducherrySouth India. Public health, 129(6), 790-796.

5. Klanja-Milievi, A., Vesin, B., Ivanovi, M., \& Budimac, Z. (2011). E-Learning personalization based on hybrid recommendation strategy and learning style identification. Computers \& Education, 56(3), 885-899.

6. Kumar, R., \& Pande, N. (2018). Assessing learning style preference of working professional cohorts in India: an empirical study using HoneyMumfords learning style questionnaire. International Journal of Indian Culture and Business Management, 16(3), 245-263.

\section{APPENDICES}

\section{PROFORMA FOR BASIC DATA}

1. "Name of the Student

2. Name of the School

3. Gender

: Boys[] Girls[]

4. School Location

5. Board

: Urban[] Rural[]

: State board[] Matriculation[]

6. Medium of study

: Tamil[] English[]

7. Family Nature

8. Father's Qualification

9. Father's Occupation

10. Mother's Qualification

11. Mother's Occupation
: Nuclear[] Joint[]

$$
\text { : }
$$

: 


\begin{tabular}{|c|c|c|c|}
\hline S. NO. & Question & \multicolumn{2}{|c|}{ Answer } \\
\hline 1 & Do you like to learn best when it is quite? & Yes & No \\
\hline 2 & Do you like to learn when there is noise in the class room? & Yes & No \\
\hline 3 & Do you like to learn by moving around the room? & Yes & No \\
\hline 4 & Do you like to learn loudly? & Yes & No \\
\hline 5 & Does anyone appreciate your learning style? & Yes & No \\
\hline 6 & Do you like to participate in group discussion? & Yes & No \\
\hline 7 & Do your learning styles help to get high marks? & Yes & No \\
\hline 8 & Do you take notes while you are learning? & Yes & No \\
\hline 9 & Do you like to learn quickly when you read subjects? & Yes & No \\
\hline 10 & Do you learn the commerce and accountancy in the same style? & Yes & No \\
\hline 11 & Do you like to learn by understanding the pe & Yes & No \\
\hline 12 & Do you like to learn by memorizing the paragraphs? & Yes & No \\
\hline 13 & Do you like to go for any special coaching centers? & Yes & No \\
\hline 14 & Do your parents help you while learning? entific & Yes & No \\
\hline 15 & Do you like to learn with case study? hand & Yes & No \\
\hline 16 & Do you write the home test after learning? & Yes & No \\
\hline 17 & Do you learn with the help of teaching aids? & Yes & No \\
\hline 18 & Do the academic achievements encourage your studies? & Yes & No \\
\hline 19 & Do your learning styles improve the academic achievements? & Yes & No \\
\hline 20 & Do the learning styles depend upon the board of education? & Yes & No \\
\hline 21 & Do the learning styles depend upon the medium of instruction? & Yes & No \\
\hline 22 & Do you like combine study? & Yes & No \\
\hline 23 & Do you learn by going to the educational visit? & Yes & No \\
\hline 24 & Do you learn additional books related to the subject? & Yes & No \\
\hline 25 & Do you verify with your teacher if you have doubts? & Yes & No \\
\hline
\end{tabular}

